\title{
Proteoglycans of cartilage
}

\author{
HELEN MUIR
}

From the Kennedy Institute of Rheumatology, Hammersmith, London

Proteoglycans are probably the most important nonfibrillar constituents of connective tissue although little is known about the proteoglycans of connective tissue other than cartilage. Hence this paper is mainly concerned with cartilage proteoglycans.

Proteoglycans are found throughout connective tissue, but those of cartilage have certain features that distinguish them from proteoglycans of other connective tissues. Cartilage is an avascular tissue in which the cells are sparsely distributed in a stiff matrix. Although the content of water is high-about $70 \%$ in the cartilage of human femoral condyles (Maroudas et al., 1969)-it is precisely the presence of water in conjunction with proteoglycans and collagen that makes cartilage resilient and elastic. Cartilage may be regarded as a reinforced fibre network which in load-bearing joints has to withstand very high repetitive loads (Freeman and Kempson, 1973).

As was first pointed out by Fessler (1960), a random macromolecular mesh (represented by proteoglycans in this instance) placed within a fibrous network (such as collagen) so that the macromolecules cannot move will impede the flow of interstitial water within the tissue when an external force is applied. Fluid pressure within cartilage rises immediately a load is applied, but as the water is driven out from the loaded area cartilage deforms only gradually because the proteoglycans entrapped in the collagen network impede the flow of interstitial water. Hence the compressive stiffness of cartilage over short intervals is directly correlated with the proteoglycan content measured as glycosaminoglycan (Kempson et al., 1970) (Fig. 1). Proteoglycans exert a swelling pressure that is constantly restrained by the collagen network in which they are entrapped. Maroudas (1975) has calculated the internal osmotic pressure of cartilage of human femoral heads to be about 3.4-3.6 atmospheres. Sorption isotherms also indicate that swelling pressure is mainly attributable to the proteoglycan component of cartilage (Mathews and Decker, 1977).

The relative proportion of collagen to proteoglycan and other constituents varies in different types of connective tissue and largely determines the physical characteristics of the tissue. Collagen accounts for about half the dry weight of fullthickness articular cartilage, but the amount decreases with depth from the articular surface (Maroudas et al., 1969; Muir et al., 1970). Conversely the proteoglycan content varies approximately inversely with the collagen content and there is a topographical variation in the overall composition of articular cartilage that appears to be characteristic of the individual (Maroudas et al., 1969; Muir et al., 1970; Kempson et al., 1973). The inverse relationship of proteoglycan and collagen contents is also clearly seen in human intervertebral discs (Adams et al., 1977).

\section{General structure of proteoglycans}

The sulphated glycosaminoglycans such as chondroitin sulphate, keratan sulphate, or dermatan sulphate are present throughout connective tissue as proteoglycans in which the glycosaminoglycan chains

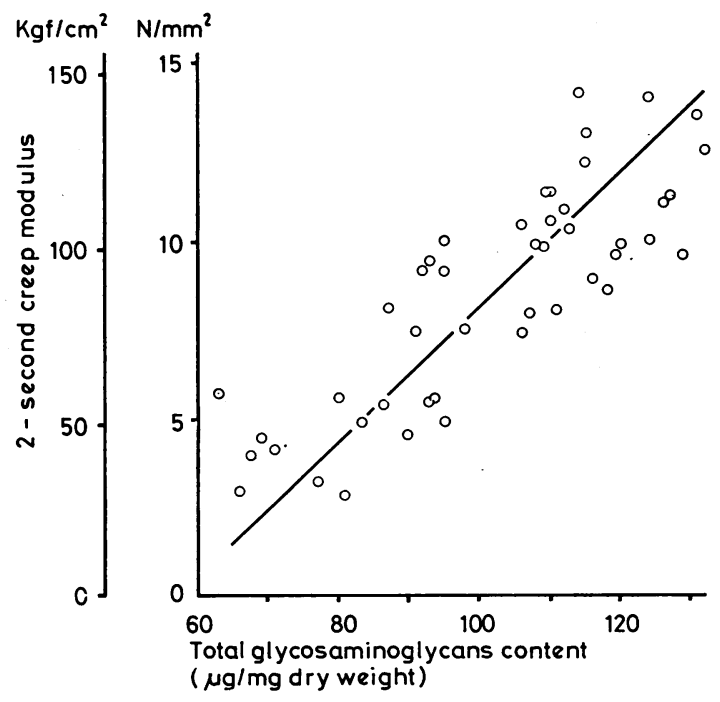

Fig. 1 Variation of creep modulus (that is, stiffness of cartilage) with total glycosaminoglycan content (from Kempson et al., 1970). 
are attached at one end to a protein core. In cartilage proteoglycans as many as $50-100$ chondroitin sulphate chains are attached laterally to a protein backbone which comprises about $10-15 \%$ of the weight of the molecule. Since the average chain weight of chondroitin sulphate is 15-20000, cartilage proteoglycans have molecular weights of about 1-3 $\times 10^{6}$ daltons (Eyring and Yang, 1968; Luscombe and Phelps, 1967; Pasternack et al., 1974). The general structure, shown diagrammatically in Fig. 2, was proposed by Mathews and Lozaityte (1958) and by Partridge et al. (1961). It is consistent with the effects of proteolytic enzymes, to which proteoglycans are particularly vulnerable (Muir, 1958), because when even a few peptide bonds are cleaved the whole molecule falls apart. The electron microscopical appearance of single molecules, spread and visualised by a special technique (Rosenberg $e t$ al., 1970a) also agrees with this general structure.

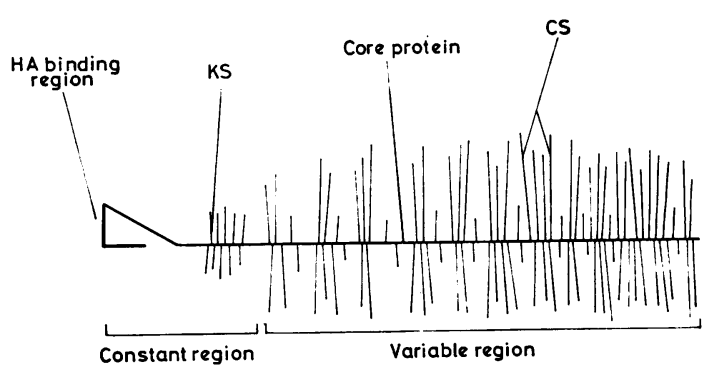

Fig. 2 Diagram of proteoglycan molecule. $H A=$ hyaluronic acid. $C S=$ chondroitin sulphate. $K S=$ keratan sulphate.

In addition to chondroitin sulphate cartilage proteoglycans contain fewer but variable numbers of keratan sulphate chains attached to the same core protein (Seno et al., 1965; Tsiganos and Muir, 1967; Heinegård and Gardell, 1967; Hoffman et al., 1967; Hascall and Riolo, 1972; Heinegård, 1972). In any given cartilage proteoglycans are heterogeneous and exhibit a range of chemical composition and molecular size. Chondroitin sulphate and all sulphated glycosaminoglycans with the exception of keratan sulphate are attached to protein via a trisaccharide sequence of neutral sugars (Fig. 3) in which xylose is glycosidically attached to the hydroxyl group of serine residues on the core protein. The complete structure of the linkage region was established by the work of Rodén (Rodén and Armand, 1966; Rodén and Smith, 1966; Helting and Rodén, 1968). Xylose, which had not previously been found in animal polysaccharides, is important in co-ordinating the synthesis of glycosaminoglycan chains with the synthesis of core protein.

\section{CHONDROITIN SULPHATE}

Chondroitin sulphate consists of repeating disaccharide units of glucuronic acid and $\mathrm{N}$-acetylgalactosamine (Fig. 4). There are about 25-30 such units in the average chain of chondroitin sulphate with almost one sulphate group per disaccharide in one of two isomeric positions. The distribution of sulphate residues along the chains is not uniform, however, as there are fewer in the vicinity of the linkage of carbohydrate to protein (Wasteson and Lindahl, 1971). In chondroitin 4-sulphate the sulphate is attached to $\mathrm{C}_{4}$ and in chondroitin 6-sulphate to $C_{6}$ of the galactosamine residues (Fig. 4). Both forms occur in articular cartilage and chondroitin 6-sulphate gradually increases with age (Hjertquist and Wasteson, 1972) in adult human articular cartilage (Mankin and Lippiello, 1971; Lust and Pronsky, 1972; Hjertquist and Lemperg, 1972; Lemperg et al., 1974). The proportions of each isomer may be deduced from the effects of specific degradative enzymes, known as chondroitinases. The results suggest that the chondroitin sulphate isomers are not present as separate chains but that the sulphate groups occupy one or other isomeric position along the same chain (Mourão and Dietrich, 1973; Seno et al., 1975; Murata and Bjelle, 1977).

The biological significance of the position of the sulphate group is not known. Both chondroitin sulphate isomers display highly ordered helical conformations when stretched films of these compounds are examined by $x$-ray fibre analysis. In chondroitin 6-sulphate, however, the sulphate groups project further from the chain than in chondroitin 4-sulphate (Isaac and Atkins, 1973; Atkins, 1977). Chondroitin

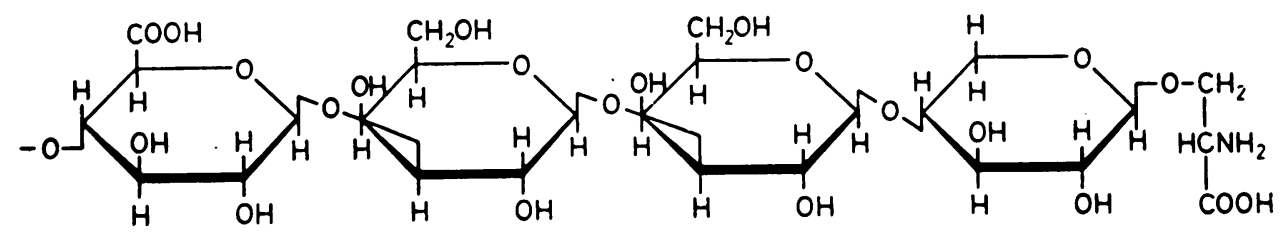

Fig. 3 Trisaccharide sequence of neutral sugars that link glycosaminoglycan chains such as chondroitin sulphate to serine residues of the core protein. 


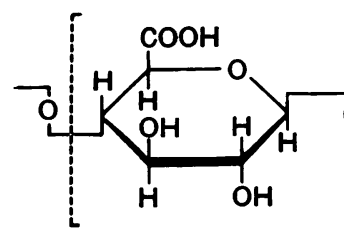

$a$

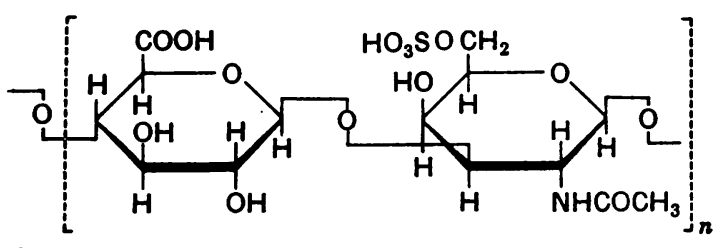

$\boldsymbol{b}$

Fig. 4 Repeating disaccharide units of $(a)$ chondroitin 4-sulphate, and (b) chondroitin 6-sulphate.

6-sulphate may therefore interact more strongly than chondroitin 4-sulphate with the basic groups of collagen and other proteins.

KERATAN SULPHATE

Keratan sulphate is found only in proteoglycans of cartilage, intervertebral discs, and cornea. It contains no uronic acid. It consists essentially of disaccharide repeating units of $\mathrm{N}$-acetylglucosamine and galactose (Fig. 5), and hence molar ratios of glucosamine:galactosamine may be used to determine the relative proportions of keratan sulphate and chondroitin sulphate in isolated proteoglucans and, less precisely, in whole cartilage. Keratan sulphate is much more variable than chondroitin sulphate both in chain length and in the degree of sulphation (reviewed by Muir and Hardingham, 1975). Skeletal keratan sulphate, also called keratan sulphate II, is distinct from corneal keratan sulphate (keratan sulphate I) in the way that it is linked to protein (Seno et al., 1965), in degree of sulphation, and in being more variable in structure (Mathews and Cifonelli, 1965). It is linked to protein through terminal galactosamine residues attached to hydroxyl groups of threonine and serine (Bray et al., 1967; Tsiganos and Muir, 1967; Hopwood and Robinson, 1974).

The sulphate groups are located on $\mathrm{C}_{6}$ of half the galactoseand more than half the glucosamine residues (Bhavanandan and Meyer, 1968). The chains of skeletal keratan sulphate are shorter and more variable in length than are chondroitin sulphate chains, having weight-average molecular weights of 5-10000 corresponding to about 13 disaccharide repeating units (Hascall and Riolo, 1972; Robinson and Hopwood, 1973). There is an excess of galactose

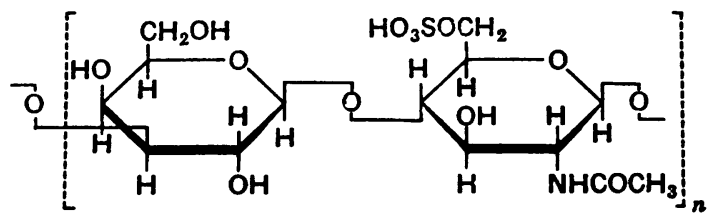

Fig. 5 Repeating disaccharide unit of keratan sulphate.

over glucosamine (Gregory and Rodén, 1961; Bhavanandan and Meyer, 1967) and there are branch points along the chain where extra galactose is attached. Small amounts of fucose (Bhavanandan and Meyer, 1968) and sialic acid (Toda and Seno, 1970; Hascall and Riolo, 1972) are also present in terminal positions.

\section{Extraction and heterogeneity of proteoglycans}

Extraction procedures developed for one kind of cartilage are not necessarily applicable to all kinds and proteoglycans are much more difficult to extract from other types of connective tissue. Much of the earlier work on proteoglycans was initiated by Schubert and his associates (Gerber et al., 1960; Pal and Schubert, 1965; Pal et al., 1966), who employed high-speed homogenisation to achieve efficient extraction when about $65 \%$ of the proteoglycan was extracted from bovine nasal cartilage.

High shearing forces degrade polymers of large molecular weight (Harrington and Zimm, 1965) and hence methods employing high-speed homogenisation have been superseded and replaced by dissociative extraction procedures first introduced by Sajdera and Hascall (1969), who examined systematically the effect of ionic strength and type of salt on the efficiency of extraction. The most effective solutions were shown to be $2 \mathrm{M} \mathrm{CaCl}_{2}, 3 \mathrm{M} \mathrm{MgCl}$, and 4M guanidinium chloride. The extracting efficiency of different salts is related to their degree of solvation (Mason and Mayes, 1973). About 80-85\% of the proteoglycans are extracted from shredded bovine nasal cartilage without homogenisation of the tissue by $4 \mathrm{M}$ guanidinium chloride. But this is less effective with articular cartilage (Rosenberg et al., 1973) particularly that of adult and elderly individualswhich needs to be ground up and briefly pulverised in liquid nitrogen for 15 seconds, when $80-85 \%$ of the proteoglycans may be extracted (Bayliss and Ali, 1978a).

Attempts to prepare discrete fractions of proteoglycans by a variety of methods have been unsuccessful. It seems that in a given cartilage there is a population of proteoglycans exhibiting a range of molecular size and chemical composition that is 
characteristic of the tissue, articular cartilage being no exception (Hardingham and Muir, 1974a; Lohmander, 1975; Hardingham et al., 1976; Roughley and Mason, 1976; Rosenberg et al., 1976; Heinegård, 1977).

When articular cartilage is extracted sequentially without high-speed homogenisation proteoglycans extracted at later steps tend to be richer in keratan sulphate and protein, although discrete fractions are not obtained (Brandt and Muir, 1971b; Šmůnek and Muir, 1972; Brandt, 1974). Operationally, three classes of proteoglycan may be distinguished, and although each class is itself heterogeneous the range of variation within a class is narrower.

A minor fraction of proteoglycans may be extracted with salt solutions of physiological ionic strength, whereas the majority need to be extracted with 'dissociating' solvents such as $4 \mathrm{M}$ guanidinium chloride. The proteoglycans that resist extraction vary in amount roughly with the collagen content of cartilage (Šmůnek and Muir, 1972). Studies of Smith et al. (1967), using high resolution electron microscopy and bismuth nitrate to stain proteoglycans in whole articular cartilage, showed that while most of the proteoglycans did not appear to be bound to collagen some were attached transversely to the fibres at two distinct positions along the $64 \mathrm{~nm}$ period. This may represent the inextractable fraction of proteoglycans.

Proteoglycans that are extracted at low ionic strength have relatively low molecular weights of about 2-3 $\times 10^{5}$ (Tsiganos and Muir, 1969) and contain less protein and keratan sulphate than the majority (Brandt and Muir, 1969, 1971a; Šimůnek and Muir, 1972; Mayes et al., 1973; Hardingham and Muir, 1974a). Using proteinase inhibitors during the extraction and purification, Pearson and Mason (1977) conclude that proteoglycans of low molecular weight do not arise from larger proteoglycans by breakdown due to the action of proteinases during the extraction. Biosynthesis experiments both in vitro (Hardingham and Muir, 1972b) and in vivo (Lohmander, 1977) also suggest that these proteoglycans are not degradation products nor precursors of larger proteoglycans. Such low molecular weight proteoglycans may be produced by mesenchymal cells in general and may not be characteristic of differentiated chondrocytes, since they are formed by prechondrogenic cells (De Luca et al., 1977). Moreover, bromodeoxyuridine, which prevents differentiation of mesenchymal cells and matrix formation (Abbott and Holtzer, 1968) arrests the synthesis of proteoglycans typical of cartilage but not the synthesis of the low molecular weight proteoglycans (Dorfman et al., 1975).

Proteoglycans that are phenotypic of cartilage are of much higher molecular weight-about 1-2.5 $\times$ $10^{6}$ daltons - and contain more protein and more keratan sulphate than proteoglycans extracted at low ionic strength or those in other kinds of connective tissue.

\section{Purification of proteoglycans by equilibrium density gradient centrifugation and dissociation of aggregates}

Equilibrium density gradient centrifugation in caesium chloride was first used to purify proteoglycans by Franek and Dunstone (1966). In this method molecules are separated according to their buoyant density in a concentrated caesium chloride gradient. Since the buoyant density of carbohydrates, particularly of polyanionic glycosaminoglycans, is much higher than that of proteins, molecules may be separated according to differences in the proportions of carbohydrate to protein. Those containing the most carbohydrate separate at the bottom of the gradient while those richer in protein separate towards the top at lower densities.

The usefulness of this method was examined by Hascall and Sajdera (1969) for the purification of nasal cartilage proteoglycans. These contain about $90 \%$ of glycosaminoglycans and have buoyant densities of about $1.8 \mathrm{~g} / \mathrm{ml}$, whereas contaminating proteins such as collagen have buoyant densities around $1.3 \mathrm{~g} / \mathrm{ml}$ and may be removed at the top of the gradient (Fig. 6). Proteoglycans of articular cartilage are richer in protein than those of nasal septum and lower starting densities must be employed to enable the majority to be separated at the bottom of the gradient (Rosenberg et al., 1973; Rosenberg, 1974; McDevitt and Muir, 1975). Density gradient centrifugation in caesium chloride is now generally carried out in two stages, the first under 'associative' conditions in $0.5 \mathrm{M}$ guanidinium chloride to purify the proteoglycans, the second under 'dissociative' conditions in $4 \mathrm{M}$ guanidinium chloride to dissociate and separate the constituents of proteoglycan aggregates.

A unique feature of cartilage proteoglycans is their ability to form multimolecular aggregates of very high molecular weight, of the order of 50 million. Detailed evidence of aggregation of highly purified proteoglycans was produced by Hascall and Sajdera (1969), although it had been proposed much earlier (Mathews and Lozaityte, 1958). It was only with the development of efficient non-disruptive methods of extraction and purification by density gradient centrifugation that unequivocal results were obtained. Hascall and Sajdera (1969) showed that proteoglycans extracted from bovine nasal cartilage with dissociating solvents such as $4 \mathrm{M}$ guanidinium chloride, dialysed to low ionic strength, and purified 

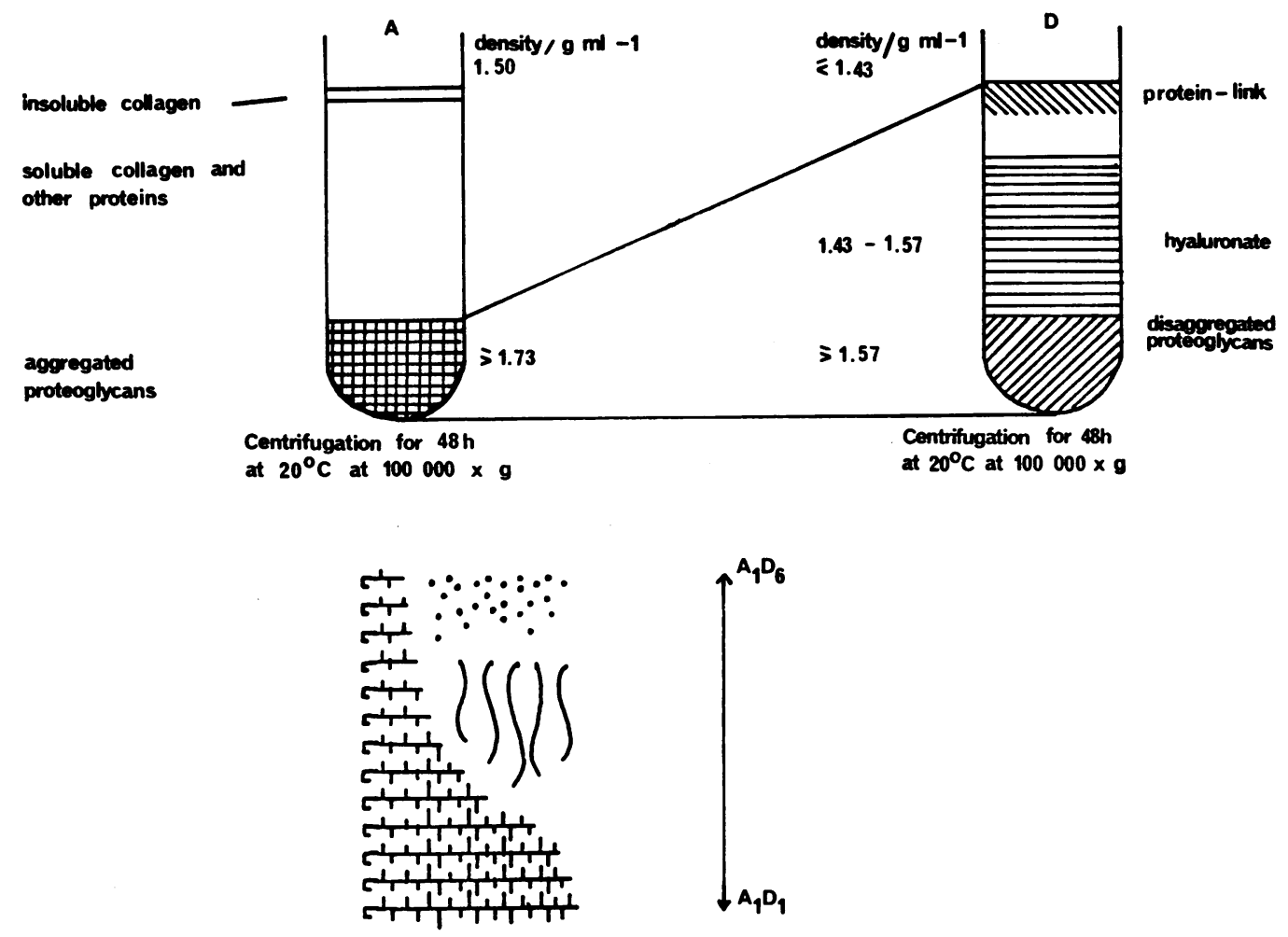

Fig. 6 Equilibrium density gradient centrifugation in caesium chloride. Associative conditions (A). Starting density usually $1.6 \mathrm{~g} / \mathrm{ml}$ or less. Dissociative conditions $(D)$. Lower fraction from associative gradient mixed with equal volume of $7.5 \mathrm{M}$ guanidinium chloride and starting density adjusted to $1.5 \mathrm{~g} / \mathrm{ml}$ with caesium chloride. Separation of molecules of decreasing size and buoyant density depicted below.

by caesium chloride density gradient centrifugation consisted of fast and more slowly sedimenting components in the analytical ultracentrifuge. When subjected to a second density gradient centrifugation under dissociative conditions in the presence of $4 \mathrm{M}$ guanidine hydrochloride about $25 \%$ of the protein, originally associated with the proteoglycan, now separated at the top of the gradient; the fast sedimenting component was no longer seen in the analytical ultracentrifuge. This showed that aggregation was not a simple self-association but involved binding to other specific non-proteoglycan components.

On dissociative density gradient centrifugation most proteoglycans separate at the bottom of the gradient but a few of progressively diminishing size are distributed throughout the gradient, the smallest being at the top (Fig. 6). In general, chondroitin sulphate content increases with molecular size whereas protein and keratan sulphate contents vary inversely with molecular size so that the smallest proteoglycans contain about $30 \%$ of protein, which is about three times more than in the largest proteoglycans. The amino-acid composition of the proteoglycans changes through the gradient. Cysteine, methionine, and aspartic acid contents increase with protein content and diminishing size, whereas serine and glycine contents decrease (Rosenberg $e t$ al., 1976). As chondroitin sulphate chains are attached to serine residues on the core protein and since the sequence Se-Gly is necessary for recognition by the xylosyltransferase that initiates the synthesis of chondroitin sulphate chains (Baker et al., 1972), there will necessarily be more serine and glycine in the larger molecules that contain more chondroitin sulphate.

The $\mathrm{pH}$ of extraction affects the proportion of aggregates finally obtained, which is maximal at pH 4.5 (Hardingham and Muir, 1974a). The proportion of aggregates is much reduced by the action of proteinases during the extraction and purification procedure so that inhibitors of cathepsins and neutral 
proteinases are now generally added during extraction and dialysis (Oegema et al., 1975). Such inhibitors should be added particularly in situations where proteinases are likely to be active.

\section{Role of hyaluronic acid in proteoglycan aggregation}

It was at first thought that proteoglycans were linked together into aggregates by interaction with a protein, referred to as 'protein-link', that separated at the top of the dissociative gradient (Hascall and Sajdera, 1969; Rosenberg et al., 1970b; Rosenberg et al., 1973). It has since been recognised, however, that aggregation depends upon a highly specific interaction of proteoglycans with hyaluronic acid, discovered by Hardingham and Muir (1972a).

The interaction with hyaluronate appears to be unique to cartilage proteoglycans and is entirely specific to hyaluronate. No other polyanions, even close isomers of hyaluronate such as chondroitin (that is, desulphated chondroitin sulphate), interact (Hascall and Heinegård, 1974b) and divalent cations are not required (Hardingham and Muir, 1972a). The interaction with hyaluronate leads to a large increase in viscosity and hydrodynamic size (Hardingham and Muir, 1972a; Hascall and Heinegård, 1974b) which enables the stoichiometry of the interaction to be examined by viscometry and gel chromatography (Hardingham and Muir, 1972a). Proteoglycans do not cross-link hyaluronate chains and hence possess only a single binding site. In cartilage where there is an excess of proteoglycan over hyaluronate a large number of proteoglycan molecules are bound to a single chain of hyaluronate which can bind as much as 250 times its weight of proteoglycan. Using average molecular weights for proteoglycans and hyaluronate of $2.5 \times 10^{6}$ and $5 \times 10^{5}$ respectively, a model for the complex was deduced (Fig. 7). It was calculated that at maximum packing each proteoglycan molecule would occupy about $20 \mathrm{~nm}$ of the length of the hyaluronate chain (Hardingham and Muir, 1974b).

Oligosaccharides of hyaluronate of the size of decasaccharides or larger compete strongly with hyaluronate; smaller oligosaccharides do not (Hardingham and Muir, 1973; Hascall and Heinegård, 1974b). The binding of proteoglycan thus involves only $5 \mathrm{~nm}$ of the hyaluronate chain. The packing of proteoglycans along the hyaluronate chain is less close because of the steric hindrance of the numerous chondroitin sulphate side chains of the proteoglycans. When these are mostly removed by chondroitinase digestion the resulting core-proteins may be packed five times more closely along the hyaluronate chain (Hascall and Heinegård, 1974b). This also shows that the chondroitin sulphate chains themselves play no part in the interaction.

When packed at high density proteoglycan molecules must lie perpendicular to the hyaluronate chain, so that the binding site must be at one end of the core protein. The hyaluronate chain thus acts as a thread holding together numerous proteoglycan molecules (Fig. 7). Electron micrographs of aggregates, published before the involvement of hyaluronate was known (Rosenberg et al., 1970a), are consistent with this interpretation.

The hyaluronate-binding region of the core protein has 5-7 intramolecular disulfide bridges (Hardingham et al., 1976) which maintain its tertiary structure. Reduction of disulfide bonds prevents aggregation (Hascall and Sajdera, 1969), and when proteoglycans are reduced and alkylated interaction with hyaluronate is abolished without change in molecular size or in protein content (Hardingham et $a l ., 1976)$. The ability to bind to hyaluronate is remarkably resistant to denaturation by heat, and, on re-oxidation of the reduced proteoglycan, loss of interaction is largely reversible (Hardingham et al., 1976). It is, however, very sensitive to specific chemical modification of basic and aromatic aminoacids. Lysine and arginine residues participate directly in the interaction but tryptophan only indirectly (Hardingham et al., 1976). When bound to hyaluronate these lysine residues are partially

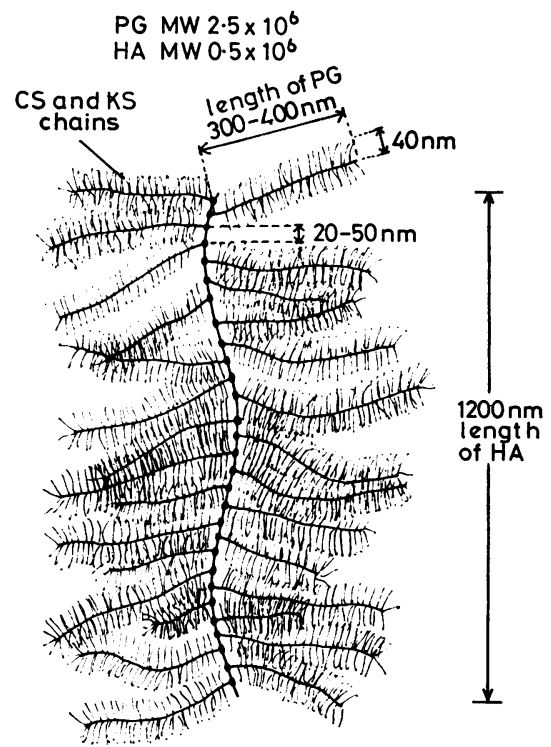

Fig. 7 Model of proteoglycan-hyaluronic acid complex. Dimensions were deduced from the stoichiometry of the interaction (Hardingham and Muir, 1974b). 
protected from chemical substitution (Heinegård and Hascall, 1977).

The exactness of the conformation of the binding site implies an equally exact conformation of the polar groups on hyaluronic acid. Binding of hyaluronate oligosaccharides to proteoglycan in competition with hyaluronate is abolished when less than $40 \%$ of the carboxyl groups on the oligosaccharides are modified or when these are displaced from the pyranose rings by three atoms (Christner et al., 1977). Since chondroitin does not compete with hyaluronate, $\mathrm{N}$-acetylglucosamine residues are also essential and cannot be substituted by $\mathrm{N}$-acetylgalactosamine residues (Hascall and Heinegård, 1974b). Together these results indicate that the effective binding site is of limited size and of precise shape enabling the maximum number of subsite interactions to take place in a small area of the molecule.

The hyaluronate binding region may be obtained by cyanogen bromide cleavage of dissociated proteoglycans (Heinegård, 1977) or by mild tryptic digestion of chondroitinase-treated aggregates (Heinegård and Hascall, 1974a). This region lacks chondroitin sulphate and has a different amino-acid composition from the whole core protein. About $60 \%$ of the remainder is accounted for by serine, glycine, proline, and glutamic acid in roughly equimolar proportions (Heinegård and Hascall, 1974a; Heinegård, 1977).

It is assumed that although proteoglycans are extremely heterogeneous in composition all those that are able to interact with hyaluronate possess the same hyaluronate binding region as an invariant part of the molecule. The region of the core protein that bears the glycosaminoglycan chains is thought to be variable in length, and to this different proportions of chondroitin sulphate and keratan sulphate are attached (Heinegård and Hascall, 1974a; Hardingham et al., 1976; Heinegård, 1977). Electron microscopical studies of articular cartilage support this idea and show molecules varying in length from 100-400 nm (Rosenberg et al., 1976; Swann et al., 1976). Proteoglycans that interact with hyaluronate thus form a series in which the hyaluronate binding region is present in molecules of all sizes (Fig. 8) since the ability to interact with hyaluronate is not restricted to any particular size of proteoglycan (Swann et al., 1976).

The hyaluronate binding region represents a greater proportion of the total molecule in smaller proteoglycans and hence the carbohydrate:protein ratio is less and the buoyant density in caesium chloride lower as the size decreases. Proteoglycans of diminishing size therefore separate at decreasing buoyant density in the dissociative gradient. In the

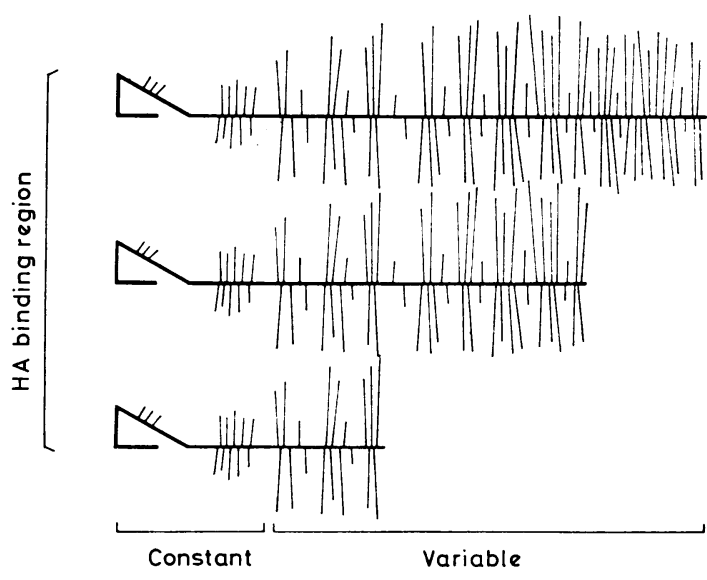

Fig. 8 Three sizes of proteoglycan showing constant hyaluronate binding region and shorter chondroitin sulphate binding region with decreasing size.

smallest proteoglycans the hyaluronate binding region represents much of the total protein (Heinegård, 1977) so that the amino-acid composition (Rosenberg et al., 1976) resembles that of the hyaluronate binding region itself as isolated by partial degradation of large proteoglycans (Heinegård and Hascall, 1974a).

The lengths of chondroitin sulphate chains do not vary significantly among proteoglycans of nonarticular cartilage of different buoyant density (Heinegård, 1977), but the lengths decrease appreciably with age in proteoglycans of human knee cartilage (Hjertquist and Wasteson, 1972). The average molecular weight was shown to decrease from 20000 in young individuals to 16000 in adult and aged persons.

Partial degradation experiments with proteolytic enzymes suggest that the chondroitin sulphate chains are located along the core protein in groups or clusters of up to 8 chains (Heinegård and Hascall, $1974 \mathrm{~b}$ ), and in proteoglycans of lower buoyant density there appear to be fewer clusters and more single chains (Heinegård, 1977). From the results of partial degradation experiments Heinegård and Hascall (1977) have proposed that most of the keratan sulphate is attached to the core protein near the hyaluronate binding region of the molecule. The preponderance of keratan sulphate in this position would explain why smaller proteoglycans that interact with hyaluronate contain more protein and keratan sulphate than larger proteoglycans.

The keratan sulphate content of articular cartilage and that of all extracted proteoglycan fractions increases with age (Šimůnek and Muir, 1972; Bjelle, 
1975; Sweet et al., 1977; Bayliss and Ali, 1978a; Inerot et al., 1978) but the function of keratan sulphate is not known. It is not essential for binding to hyaluronate since proteoglycans from rat chondrosarcoma lack keratan sulphate but are nevertheless capable of aggregation (Oegema et al., 1975).

\section{Role of link protein in aggregation}

The interaction of proteoglycans with hyaluronate is an equilibrium which lies well in favour of complex formation under physiological conditions of ionic strength, temperature, and $\mathrm{pH}$ (Hardingham and Muir, 1972a, 1975). But the complex is unstable in the ultracentrifuge, unlike the aggregate (Gregory, 1973) which contains a third component, the 'protein-link', that accounts for about a quarter of the protein of the aggregate (Hascall and Sajdera, 1969). The protein link appears to function in stabilising the proteoglycan-hyaluronate complex so that it is no longer in equilibrium with its dissociation products. This is illustrated by the fact that aggregates are unaffected by oligosaccharides of hyaluronate which dissociate the proteoglycan-hyaluronate complex (Hascall and Heinegård, 1974b) (Fig. 9). The protein-link binds to proteoglycan (Caterson and Baker, 1978) but it does not promote aggregation on its own (Tsiganos et al., 1972). It also binds to hyaluronate in the absence of proteoglycan (Oegema et al., 1977). It appears to be present in aggregates in $1: 1$ ratio with proteoglycan, as deduced from partial degradation of aggregates (Heinegård and Hascall, 1974a). Two closely related link proteins have been isolated with molecular weights of 47000 and 51000 which give the same peptides on $\mathrm{CNBr}$ cleavage (Baker and Caterson, 1977).

Proteoglycan aggregation as currently envisaged, with the participation of three components, is depicted in Fig. 10. The size of a given aggregate will thus depend on the size of proteoglycan molecules but principally on the length of the hyaluronate chain and on the number of proteoglycans attached to it.

The biological function of proteoglycan aggregation is unknown, but as it is apparently restricted to the proteoglycans of cartilage its role is presumably peculiar to the function of cartilage. The size of aggregates immobilises them very effectively in the collagen network and aggregated proteoglycans must first be dissociated before they can be extracted. Aggregates may be less compressible than monomers and may therefore make a greater contribution to the compressive stiffness of cartilage.

Aggregates are more resistant to attack by proteinases, since controlled partial degradation is possible only with proteoglycan aggregates whereas

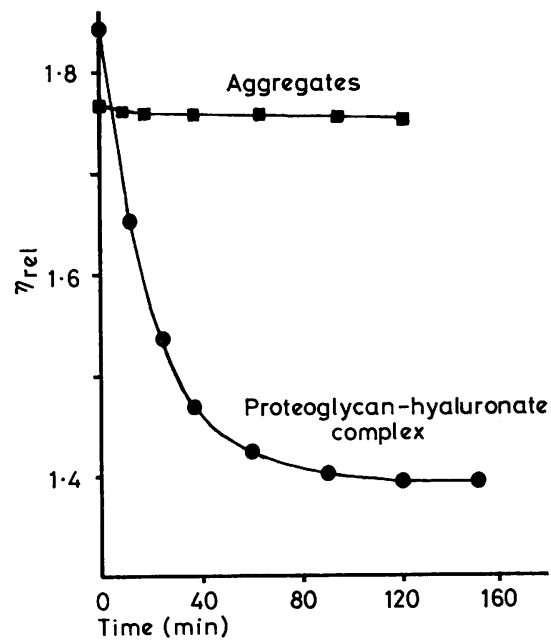

Fig. 9 Effect of hyaluronate oligosaccharides on viscosity of proteoglycan aggregates and of proteoglycanhyaluronate complex in $0.5 \mathrm{M}$ guanidinium chloride at $30^{\circ} \mathrm{C}$ (Hardingham, unpublished results).

monomers are completely broken down (Hascall and Heinegård, 1974a; Heinegård and Hascall, 1974a). Aggregates may therefore be catabolised more slowly. They may also indirectly play some part in regulating proteoglycan synthesis by chondrocytes, since free hyaluronic acid, but not that bound up in aggregates; inhibits proteoglycan synthesis (Wiebkin et al., 1975).

\section{Metabolic control mechanism}

The synthetic activity of chondrocytes is influenced by their immediate surroundings and they respond to losses of proteoglycans from their matrix by increased synthesis. When returned to normal medium after exposure to papain (Bosmann, 1968) or hyaluronidase (Fitton-Jackson, 1970) embryonic chick cartilage in organ culture responded by increased synthesis, so that the loss was replenished within a few days (Hardingham et al., 1972). Conversely, Handley and Lowther (1977) found that $5-10 \mathrm{mg} / \mathrm{ml}$ of proteoglycans added to the medium of chick embryonic chondrocyte cultures considerably depressed proteoglycan synthesis. Much lower levels of hyaluronate significantly reduced proteoglycan synthesis by chondrocytes from cartilage of adult pig (Wiebkin and Muir, 1973) or embryonic chick (Toole, 1973; Solursh et al., 1974; Handley and Lowther, 1976). The effect was specific to hyaluronate and involved material on the cell membrane that was destroyed by trypsin but not by chondroitinase 


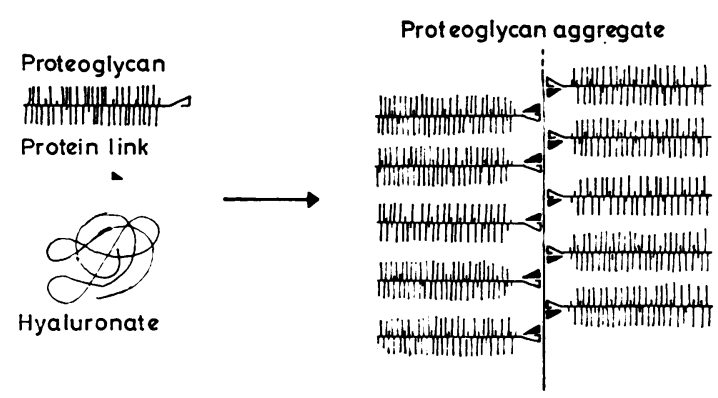

Fig. 10 Diagram of aggregation.

(Wiebkin and Muir, 1975). It has been suggested that either the synthesis of core protein or the first step in chondroitin sulphate chain synthesis may be inhibited (Handley and Lowther, 1976).

Both collagen and proteoglycans have been shown by autoradiography to be synthesised by chondrocytes, but how the syntheses are co-ordinated is not known. Over short periods of time in vitro the synthesis of one was unaffected by inhibition of the synthesis of the other (Dondi and Muir, 1976) and hence the two processes are not closely interdependent.

\section{Degradative processes}

During normal turnover the catabolism of proteoglycans and other constituents of cartilage must be brought about by cells within the tissue. The structure of proteoglycans makes them particularly vulnerable to attack by proteolytic enzymes (Fig. 2) and different proteolytic enzymes reduce the viscosity of proteoglycan solutions to different degrees (Muir, 1958). Many lysosomal proteinases are now well characterised and have been shown to degrade proteoglycans to fragments of different size (Morrison et al., 1973; Malemud and Janoff, 1975; Keiser et al., 1976). However, proteinases active at neutral $\mathrm{pH}$ are likely to be principally involved in normal turnover of proteoglycans (Sapolsky et al., 1974; Sapolsky et al., 1976).

Cathepsin B, a neutral thiol proteinase, is present in human articular cartilage in high levels in juveniles but fall to low levels in adults (Bayliss and Ali, 1978b). In rheumatoid arthritis inflammatory cells infiltrate the joint; they include polymorphonuclear leucocytes which contain neutral proteinases (reviewed by Harris and Cartwright, 1977) that degrade proteoglycans in whole cartilage (Malemud and Janoff, 1975). Cartilage is normally impermeable to large solutes such as proteins (Maroudas, 1973) because proteoglycans exclude large molecules from their domains. But when degraded by proteolytic enzymes their size is reduced so much that they can diffuse out from the cartilage, so allowing penetration of proteolytic enzymes and further degradation of the tissue. The collagen fibres are then exposed to the effects of collagenase released from inflammatory cells.

How far cathepsin D participates in normal turnover is not clear. During autolysis (Dingle et al., 1972) or exposure to excess vitamin A (Poole et al., 1974), which stimulates the release of lysosomal enzymes, the loss of proteoglycans from cartilage matrix is attributable to the action of cathepsin $D$, whose extracellular localisation has been shown by immunofluorescence using specific antisera to cathepsin D (Poole et al., 1974).

Normal cartilage contains proteinase inhibitors, among which are low molecular weight cationic proteins (Kuettner et al., 1974; Kuettner et al., 1976; Kuettner et al., 1977) and other specific inhibitors (Roughley et al., 1978). Probably such proteinase inhibitors would normally modulate the activity of proteinases. These may be released not only from inflammatory cells but also from cells of the soft tissues of the joint, particularly in the presence of immune complexes (Fell and Barratt, 1973; Poole et al., 1973). In such situations the inhibitors may be overwhelmed by the influx of proteinases. Moreover, in organ cultures of normal cartilage chondrocytes are stimulated to degrade their surrounding matrix by some factor that emanates from synovial tissue (Fell and Jubb, 1977).

Partially degraded proteoglycans which diffuse out from cartilage and enter the circulation are rapidly removed by the liver and completely broken down (Wood et al., 1973). The liver is able to catabolise all the proteoglycan released during normal turnover and only a very small proportion of the total reaches the urine (Wood et al., 1973).

\section{Osteoarthrosis}

In osteoarthrosis in man and domestic animals the proportion of aggregated proteoglycans is less than normal (Brandt et al., 1976; Palmoski and Brandt, 1976; Inerot et al., 1978) and the monomeric proteoglycans are smaller and more heterogeneous (Sweet et al., 1977; Inerot et al., 1978) while the chondroitin sulphate chains are abnormally short and heterogeneous (Hjertquist and Wasteson, 1972). Both in whole cartilage and in the proteoglycans extracted from osteoarthrotic cartilage the proportion of chondroitin sulphate relative to keratan sulphate is invariably higher than normal (Mankin and Lippiello, 1971; Brandt, 1974; McDevitt and Muir, 1974, 1975, 1976; Palmoski and Brandt, 1976; 
Brandt et al., 1976; Sweet et al., 1977; Bayliss and Ali, 1978a) but the significance of this change is unknown. The rates of incorporation of ${ }^{3} \mathrm{H}-$ thymidine and ${ }^{35} \mathrm{SO}_{4}$ are closely correlated (Mankin and Lippiello, 1971) and Mankin et al. (1971) have suggested that in osteoarthrosis chondrocytes revert to a chondroblastic phase, undergo cell division, and start to synthesise proteoglycans characteristic of immature cartilage in that these contain less keratan sulphate relative to chondroitin sulphate than proteoglycans of mature cartilage of comparable age.

Degradative enzymes produced by chondrocytes themselves may play some part in the destruction of cartilage. The activity of cathepsin B was found to be considerably raised in specimens of osteoarthrotic cartilage of human femoral heads removed for total hip replacement compared with normal cartilage of comparable age taken from fractured femoral heads (Bayliss and Ali, 1978b). Osteoarthrotic changes occur first in certain discrete areas of the femoral head (Byers et al., 1970), and in these areas the activity of cathepsin D was much higher than in visibly normal surrounding areas (Ali and Evans, 1973).

The changes seen in osteoarthrosis and in mineralisation of cartilage are similar in certain respects. In both cases proteoglycan content decreases (Lohmander and Hjerpe, 1975), the qualitative changes in proteoglycans are similar, and alkaline phosphatase activity is greatly raised (Ali and Evans, 1973; Howell et al., 1976), particularly in osteophytic cartilage (Bayliss and Ali, 1978b). Alkaline phosphatase activity in human articular cartilage is largely in matrix vesicles (Ali, 1976), and vesicles containing hydroxyapatite crystallites are present in the deep zone of osteoarthrotic human cartilage. Calcification of this zone would then allow the advance of a mineral front and remodelling of subchondral bone (Ali, 1977). It is notable that loss of aggregation is a feature of osteoarthrosis and that the growth of apatite crystals is thought to be inhibited by proteoglycan aggregates (Cuervo et al., 1973). It is not yet certain, however, how far qualitative changes in proteoglycans and changes in mineral metabolism are strictly interdependent.

The initial stages of osteoarthrosis cannot be studied in the natural disease because it is impossible to know when it began. Using an experimentally induced osteoarthrosis in the dog that closely resembles the natural disease it has been possible to study the earliest biochemical changes that precede the appearance of lesions, since these develop in the same area of the tibial condyle in each animal. This region can therefore be sampled before lesions appear (McDevitt and Muir, 1974, 1975, 1976; McDevitt $e t$ al., 1977). Increased hydration of the cartilage was a primary change and consequently the proteoglycans were more extractable. Profound metabolic changes took place and proteoglycans of different chemical composition were produced. It appeared that there were three phases in the early development of the disease (Muir, 1977). Only by the third phase, when osteophytes first appear at the joint margins, would the disease be recognised as osteoarthrosis by its gross and microscopic appearances, although at this stage the disease is far less advanced than that seen in human clinical osteoarthrosis.

\section{References}

Abbott, J., and Holtzer, H. (1968). The loss of phenotypic traits by differentiated cells. V The effect of 5-bromodeoxyuridine on cloned chondrocytes. Proceedings of the National Academy of Sciences of the United States of America, 59, 1144-1151.

Adams, P., Eyre, D. R., and Muir, H. (1977). Biochemical aspects of development and ageing of human lumbar intervertebral discs. Rheumatology and Rehabilitation, 16, 22-29.

Ali, S. Y. (1976). Analysis of matrix vesicles and their role in the calcification of epiphyseal cartilage. Federation Proceedings, 35, 135-142.

Ali, S. Y. (1977). Matrix vesicles and apatite nodules in arthritic cartilage. In Perspectives in Inflammation. Future Trends and Developments, edited by D. A. Willoughby, J. P. Giroud, and G. P. Velo, pp. 211-223. MTP Press, Lancaster.

Ali, S. Y., and Evans, L. (1973). Enzymic degradation of cartilage in oesteoarthritis. Federation Proceedings, 32, 1494-1498.

Atkins, E. D. T. (1977). Molecular architecture of the animal and some microbial extracellular polysaccharides. In First Cleveland Symposium on Macromolecules, edited by A. G. Walton. Elsevier, Amsterdam.

Baker, J., and Caterson, B. (1977). The purification and cyanogen bromide cleavage of the 'link-proteins' from cartilage proteoglycan. Biochemical and Biophysical Research Communications, 77, 1-10.

Baker, J. R., Rodén, L., and Stoolmiller, A. C. (1972). Biosynthesis of chondroitin sulfate proteoglycan: xylosyl transfer to Smith-degraded cartilage proteoglycan and other exogenous acceptors. Journal of Biological Chemistry, 247, 3838-3847.

Bayliss, M. T., and Ali, S. Y. (1978a). Isolation of proteoglycans from human articular cartilage. Biochemical Journal, 169, 123-132.

Bayliss, M. T., and Ali, S. Y. (1978b). Studies on cathepsin B in human articular cartilage. Biochemical Journal, 171, 149-154.

Bhavanandan, V. P., and Meyer, K. (1967). Studies on keratosulfates: methylation and partial acid hydrolysis of bovine corneal keratosulfate. Journal of Biological Chemistry, 242, 4352-4359.

Bhavanandan, V. P., and Meyer, K. (1968). Studies on keratosulfates: methylation, desulfation, and acid hydrolysis studies on old human rib cartilage kerato- 
sulfate. Journal of Biological Chemistry, 243, 1052-1059.

Bjelle, A. (1975). Content and composition of glycosaminoglycans in human knee joint cartilage: variation with site and age in adults. Connective Tissue Research, 3, 141-147.

Bosmann, H. B. (1968). Cellular control of macromolecular synthesis: rates of synthesis of extracellular macromolecules during and after depletion by papain. Proceedings of the Royal Society of London. Series B. Biological Sciences, 169, 399-425.

Brandt, K. D. (1974). Enhanced extractability of articular cartilage proteoglycans in osteoarthrosis. Biochemical Journal, 143, 475-478.

Brandt, K. D., and Muir, H. (1969). Characterisation of protein-polysaccharides of articular cartilage from mature and immature pigs. Biochemical Journal, 114, 871-876.

Brandt, K. D., and Muir, H. (1971a). Heterogeneity of protein-polysaccharides of porcine articular cartilage: the sequential extraction of chondroitin sulphateproteins with iso-osmotic neutral sodium acetate. Biochemical Journal, 121, 261-270.

Brandt, K. D., and Muir, H. (1971b). Heterogeneity of protein-polysaccharides of porcine articular cartilage: the chondroitin sulphate proteins associated with collagen. Biochemical Journal, 123, 747-755.

Brandt, K. D., Palmoski, M. J., and Perricone, E. (1976). Aggregation of cartilage proteoglycans. II Evidence for the presence of a hyaluronate-binding region on proteoglycans from osteoarthritic cartilage. Arthritis and Rheumatism, 19, 1308-1314.

Bray, B. A., Lieberman, R., and Meyer, K. (1967). Structure of human skeletal keratosulfate: the linkage region. Journal of Biological Chemistry, 242, 3373-3380.

Byers, P. D., Contepomi, C. A., and Farkas, T. A. (1970). A post mortem study of the hip joint. Annals of the Rheumatic Diseases, 29, 15-31.

Caterson, B., and Baker, J. (1978). The interaction of link proteins with proteoglycan monomers in the absence of hyaluronic acid. Biochemical and Biophysical Research Communications, 80, 496-503.

Christner, J. E., Brown, M. L., and Dziewiatkowski, D. D. (1977). Interaction of cartilage proteoglycans with hyaluronic acid: the role of the hyaluronic acid carboxyl groups. Biochemical Journal, 167, 711-716.

Cuervo, L. A., Pita, J. C., and Howell, D. S. (1973). Inhibition of calcium phosphate mineral growth by proteoglycan aggregate fractions in a synthetic lymph. Calcified Tissue Research, 13, 1-10.

De Luca, S., Heinegård, D. Hascall, V. C., Kimura, J. H., and Caplan, A. I. (1977). Chemical and physical changes in proteoglycans during development of chick limb bud chondrocytes grown in vitro. Journal of Biological Chemistry, 252, 6600-6608.

Dingle, J. T., Barrett, A. J., Poole, A. R., and Stovin, P. (1972). Inhibition by pepstatin of human cartilage degradation. Biochemical Journal, 127, 443-444.

Dondi, P. G., and Muir, H. (1976). Collagen synthesis and deposition in cartilage during disrupted proteoglycan production. Biochemical Journal, 160, 117-120.

Dorfman, A., Levitt, D., Schwartz, N. B., and Ho, P. L. (1975). Studies on cartilage differentiation. In Extra- cellular Matrix Influences on Gene Expression, edited by $H$. C. Slavkin and R. C. Greulich, pp. 19-23. Academic Press, New York.

Eyring, E. J., and Yang, J. T. (1968). Conformation of protein-polysaccharide complex from bovine nasal septum. Journal of Biological Chemistry, 243, 13061311.

Fell, H. B., and Barratt, M. E. J. (1973). The role of soft connective tissue in the breakdown of pig articular cartilage cultivated in the presence of complementsufficient antiserum to pig erythrocytes. I. Histological changes. International Archives of Allergy, 44, 441-468.

Fell, H. B., and Jubb, R. W. (1977). Effect of synovial tissue on the breakdown of articular cartilage in organ culture. Arthritis and Rheumatism, 20, 1359-1371.

Fessler, J. H. (1960). A structural function of mucopolysaccharide in connective tissue. Biochemical Journal, 76, 124-132.

Fitton-Jackson, S. (1970). Environmental control of macromolecular synthesis in cartilage and bone: morphogenetic response to hyaluronidase. Proceedings of the Royal Society of London. Series B. Biological Sciences, 175, 405-453.

Franek, M. D., and Dunstone, J. R. (1966). Densitygradient centrifugation in the isolation of polysaccharide-protein complexes from aortic tissue. Biochimica et Biophysica Acta, 127, 213-222.

Freeman, M. A. R., and Kempson, G. E. (1973). Load carriage. In Adult Articular Cartilage, edited by M. A. R. Freeman, pp. 228-246. Pitman Medical, London.

Gerber, B. R., Franklin, E. C., and Schubert, M. (1960). Ultracentrifugal fractionation of bovine nasal chondromucoprotein. Journal of Biological Chemistry, 235, 2870-2875.

Gregory, J. D. (1973). Multiple aggregation factors in cartilage proteoglycan. Biochemical Journal, 133, 383-386.

Gregory, J. D., and Rodén, L. (1961). Isolation of keratosulfate from chondromucoprotein of bovine nasal septa. Biochemical and Biophysical Research Communications, 5, 430-434.

Handley, C. J., and Lowther, D. A. (1976). Inhibition of proteoglycan synthesis by hyaluronic acid in chondrocytes in cell culture. Biochimica et Biophysica Acta, 444, 69-74.

Handley, C. J., and Lowther, D. A. (1977). Extracellular matrix metabolism by chondrocytes. III Modulation of proteoglycan synthesis by extracellular levels of proteoglycan in cartilage cells in culture. Biochimica et Biophysica Acta, 500, 132-139.

Hardingham, T. E., Ewins, R. J. F., and Muir, H. (1976). Cartilage proteoglycans: structure and heterogeneity of the protein core and the effects of specific protein modifications on the binding to hyaluronate. Biochemical Journal, 157, 127-143.

Hardingham, T. E., Fitton-Jackson, S., and Muir, H. (1972). Replacement of proteoglycans in embryonic chicken cartilage in organ culture after treatment with testicular hyaluronidase. Biochemical Journal, 129, 101-112.

Hardingham, T. E., and Muir, H. (1972a). The specific 
interaction of hyaluronic acid with cartilage proteoglycans. Biochimica et Biophysica Acta, 279, 401-405.

Hardingham, T. E., and Muir, H. (1972b). Biosynthesis of proteoglycans in cartilage slices: fractionation by gel chromatography and equilibrium density-gradient centrifugation. Biochemical Journal, 126, 791-803.

Hardingham, T. E., and Muir, H. (1973). Binding of oligosaccharides of hyaluronic acid to proteoglycans. Biochemical Journal, 135, 905-908.

Hardingham, T. E., and Muir, H. (1974a). Hyaluronic acid in cartilage and proteoglycan aggregation. Biochemical Journal, 139, 565-581.

Hardingham, T. E., and Muir, H. (1974b). The function of hyaluronic acid in proteoglycan aggregation. In Normal and Osteoarthrotic Articular Cartilage, edited by S. Y. Ali, M. W. Elves, and D. H. Leaback, pp. 51-58. Institute of Orthopaedics, Stanmore.

Hardingham, T. E., and Muir, H. (1975). Structure and stability of proteoglycan aggregates. Annals of the Rheumatic Diseases, 34, Suppl 2, 26-28.

Harrington, R. E., and Zimm, B. H. (1965). Degradation of polymers by controlled hydrodynamic shear. Journal of Physical Chemistry, 69, 161-175.

Harris, E. D., and Cartwright, E. C. (1977). Collagenases. In Proteinases in Mammalian Cells and Tissues, edited by A. J. Barrett, pp. 249-283. North-Holland Publishing, Amsterdam and Oxford.

Hascall, V. C., and Heinegård, D. (1974a). Aggregation of cartilage proteoglycans. I The role of hyaluronic acid. Journal of Biological Chemistry, 249, 4232-4241.

Hascall, V. C., and Heinegård, D. (1974b). Aggregation of cartilage proteoglycans. II Oligosaccharide competitors of the proteoglycan-hyaluronic acid interaction. Journal of Biological Chemistry, 249, 4242-4249.

Hascall, V. C., and Riolo, R. L. (1972). Characteristics of the protein-keratan sulfate core and of keratan sulfate prepared from bovine nasal cartilage proteoglycan. Journal of Biological Chemistry, 247, 4529-4538.

Hascall, V. C., and Sajdera, S. W. (1969). Proteinpolysaccharide complex from bovine nasal cartilage: the function of glycoprotein in the formation of aggregates. Journal of Biological Chemistry, 244, 2384-2396.

Heinegård, D. (1972). Hyaluronidase digestion and alkaline treatment of bovine tracheal cartilage proteoglycans: isolation and characterisation of different keratan sulfate proteins. Biochimica et Biophysica Acta, 285, 193-207.

Heinegård, D. (1977). Polydispersity of cartilage proteoglycans: structural variations with size and buoyant density of the molecules. Journal of Biological Chemistry, 252, 1980-1989.

Heinegård, D., and Gardell, S. (1967). Studies on proteinpolysaccharide complex (proteoglycan) from human nucleus pulposus. I. Isolation and preliminary characterisation. Biochimica et Biophysica Acta, 148, 164-171.

Heinegård, D., and Hascall, V. C. (1974a). Aggregation of cartilage proteoglycans. III Characteristics of the proteins isolated from trypsin digests of aggregates. Journal of Biological Chemistry, 249, 4250-4256.

Heinegård, D., and Hascall, V. C. (1974b). Characterisation of chondroitin sulfate isolated from trypsinchymotrypsin digests of cartilage proteoglycans.
Archives of Biochemistry and Biophysics, 165, 427-441. Heinegård, D., and Hascall, V. C. (1977). Personal communication.

Helting, T., and Rodén, L. (1968). The carbohydrateprotein linkage region of chondroitin 6-sulfate. Biochimica et Biophysica Acta, 170, 301-308.

Hjertquist, S. O., and Lemperg, R. (1972). Identification and concentration of the glycosaminoglycans of human articular cartilage in relation to age and osteoarthrosis. Calcified Tissue Research, 10, 223-237.

Hjertquist, S. O., and Wasteson, $\AA$. (1972). The molecular weight of chondroitin sulphate from human articular cartilage. Calcified Tissue Research, 10, 31-37.

Hoffman, P., Mashburn, T. A., Jr., and Meyer, K. (1967). Proteinpolysaccharide of bovine cartilage. II The relation of keratan sulfate and chondroitin sulfate. Journal of Biological Chemistry, 242, 3805-3809.

Hopwood, J. J., and Robinson, H. C. (1974). The structure and composition of cartilage keratan sulphate. Biochemical Journal, 141, 517-526.

Howell, D. S., Muniz, O., Pita, J. C., and Enis, J. E. (1976). Pyrophosphate release by osteoarthritis cartilage incubates. Arthritis and Rheumatism, 19, 488-494.

Inerot, S., Heinegård, D., Audell, L., and Olsson, S. E. (1978). Articular-cartilage proteoglycans in aging and osteoarthritis. Biochemical Journal, 169, 143-156.

Isaac, D. H., and Atkins, E. D. T. (1973). Molecular conformations of chondroitin-4-sulphate. Nature New Biology, 244, 252-253.

Keiser, H., Greenwald, R. A., Feinstein, G., and Janoff, A. (1976). Degradation of cartilage proteoglycan by human leukocyte granule neutral proteases-a model of joint injury. II Degradation of isolated bovine nasal cartilage proteoglycan. Journal of Clinical Investigation, 57, 625-632.

Kempson, G. E., Muir, H., Pollard, C., and Tuke, M. (1973). The tensile properties of the cartilage of human femoral condyles related to the content of collagen and glycosaminoglycans. Biochimica et Biophysica Acta, 297, 456-472.

Kempson, G. E., Muir, H., Swanson, S. A., and Freeman, M. A. R. (1970). Correlations between stiffness and the chemical constituents of cartilage on the human femoral head. Biochimica et Biophysica Acta, 215, 70-77.

Kuettner, K. E., Croxen, R. L., Eisenstein, R., and Sorgente, N. (1974). Proteinase inhibitor activity in connective tissues. Experientia, 30, 595-597.

Kuettner, K. E., Harper, E., and Eisenstein, R. (1977). Protease inhibitors in cartilage. Arthritis and Rheumatism, 20, 124-132.

Kuettner, K. E., Hiti, J., Eisenstein, R., and Harper, E. (1976). Collagenase inhibition by cationic proteins derived from cartilage and aorta. Biochemical and Biophysical Research Communications, 72, 40-46.

Lemperg, R. K., Larsson, S. E., and Hjertquist, S. O. (1974). The glycosaminoglycans of bovine articular cartilage. I Concentration and distribution in different layers in relation to age. Calcified Tissue Research, 15, 237-251.

Lohmander, S. (1975). Proteoglycans of guinea-pig costal 
cartilage: fractionation and characterisation. European Journal of Biochemistry, 57, 549-559.

Lohmander, S. (1977). Turnover of proteoglycans in guinea-pig costal cartilage. Archives of Biochemistry and Biophysics, 180, 93-101.

Lohmander, S., and Hjerpe, A. (1975). Proteoglycans of mineralising rib and epiphyseal cartilage. Biochimica et Biophysica Acta, 404, 93-109.

Luscombe, M., and Phelps, C. F. (1967). The composition and physico-chemical properties of bovine nasal-septa protein-polysaccharide complex. Biochemical Journal, 102, 110-119.

Lust, G., and Pronsky, W. (1972). Glycosaminoglycan contents of normal and degenerative articular cartilage from dogs. Clinica Chimica Acta, 39, 281-286.

McDevitt, C. A., Gilbertson, E. M. M., and Muir, H. (1977). An experimental model of osteoarthritis: early morphological and biochemical changes. Journal of Bone and Joint Surgery, 59B, 24-35.

McDevitt, C. A., and Muir, H. (1974). A biochemical study of experimental and natural osteoarthrosis. In Biopolymere und Biomechanik von Bindegewebssystemen, edited by F. Hartmann, C. Hartung, and H. Zeidler, pp. 261-267. Springer-Verlag, Berlin and New York.

McDevitt, C. A., and Muir, H. (1975). The proteoglycans of articular cartilage in early experimental osteoarthrosis. Protides of Biological Fluids, 22, 269-274.

McDevitt, C. A., and Muir, H. (1976). Biochemical changes in the cartilage of the knee in experimental and natural osteoarthritis in the dog. Journal of Bone and Joint Surgery, 58B, 94-101.

Malemud, C. J., and Janoff, A. (1975). Identification of neutral proteases in human neutrophil granules that degrade articular cartilage proteoglycan. Arthritis and Rheumatism, 18, 361-368.

Mankin, H. J., Dorfman, H., Lippiello, L., and Zarins, A. (1971). Biochemical and metabolic abnormalities in articular cartilage from osteo-arthritic human hips. II. Correlation of morphology with biochemical and metabolic data. Journal of Bone and Joint Surgery, 53A, 523-537.

Mankin, H. J., and Lippiello, L. (1971). The glycosaminoglycans of normal and arthritic cartilage. Journal of Clinical Investigation, 50, 1712-1719.

Maroudas, A. (1973). Physico-chemical properties of articular cartilage. In Adult Articular Cartilage, edited by M. A. R. Freeman, pp. 131-170. Pitman Medical Publications, London.

Maroudas, A. (1975). Biophysical chemistry of cartilaginous tissues with special reference to solute and fluid transport. Biorheology, 12, 233-248.

Maroudas, A., Muir, H., and Wingham, J. (1969). The correlation of fixed negative charge with glycosaminoglycan content of human articular cartilage. Biochimica et Biophysica Acta, 177, 492-500.

Mason, R. M., and Mayes, R. W. (1973). Extraction of cartilage proteinpolysaccharides with inorganic salt solutions. Biochemical Journal, 131, 535-540.

Mathews, M. B., and Cifonelli, J. A. (1965). Comparative biochemistry of keratosulfates. Journal of Biological Chemistry, 240, 4140-4145.

Mathews, M. B., and Decker, L. (1977). Comparative studies of water sorption of hyaline cartilage. Biochimica et Biophysica Acta, 497, 151-159.

Mathews, M. B., and Lozaityte, I. (1958). I Sodium chondroitin sulfate-protein complexes of cartilage. II. Molecular weight and shape. Archives of Biochemistry and Biophysics, 74, 158-174.

Mayes, R. W., Mason, R. M., and Griffin, D. C. (1973). The composition of cartilage proteoglycans: an investigation using high- and low-ionic-strength extraction procedures. Biochemical Journal, 131, 541-553.

Morrison, R. I. G., Barrett, A. J., Dingle, J. T., and Prior, D. (1973). Cathepsins $B_{1}$ and $D$ : action on human cartilage proteoglycans. Biochimica et Biophysica Acta, 302, 411-419.

Mourão, P. A. S., and Dietrich, C. P. (1973). Differences in the content of chondroitin sulfate $\mathrm{C}$ and chondroitin sulfate $A$ in the epiphyseal growth cartilages of human vertebrae and long bones. Biochimica et Biophysica Acta, 320, 210-213.

Muir, H. (1958). The nature of the link between protein and carbohydrate of a chondroitin sulphate complex from hyaline cartilage. Biochemical Journal, 69, 195-204.

Muir, H. (1977). Molecular approach to the understanding of osteoarthrosis. Annals of the Rheumatic Diseases, 36, 199-208.

Muir, H., Bullough, P., and Maroudas, A. (1970). The distribution of collagen in human articular cartilage with some of its physiological implications. Journal of Bone and Joint Surgery, 52B, 554-563.

Muir, H., and Hardingham, T. E. (1975). Structure of proteoglycans. In Biochemistry of Carbohydrates, (MTP International Review of Science-Biochemistry. Series 1, Vol. 5), edited by W. J. Whelan, pp. 153-222. Butterworth, London.

Murata, K., and Bjelle, A. O. (1977). Constitutional heterogeneity of the glycosaminoglycans in articular cartilage proteoglycans. Connective Tissue Research, 5, 109-116.

Oegema, T. R., Jr., Brown, M., and Dziewiatkowski, D. D. (1977). The link protein in proteoglycan aggregates from the Swarm rat chondrosarcoma. Journal of Biological Chemistry, 252, 6470-6477.

Oegema, T. R., Jr., Hascall, V. C., and Dziewiatkowski, D. D. (1975). Isolation and characterisation of proteoglycans from the Swarm rat chondrosarcoma. Journal of Biological Chemistry, 250, 6151-6159.

Pal, S., Doganges, P. T., and Schubert, M. (1966). The separation of new forms of the proteinpolysaccharides of bovine nasal cartilage. Journal of Biological Chemistry, 241, 4261-4266.

Pal, S., and Schubert, M. (1965). The action of hydroxylamine on the proteinpolysaccharides of cartilage. Journal of Biological Chemistry, 240, 3245-3248.

Palmoski, M., and Brandt, K. D. (1976). Hyaluronate binding by proteoglycans: comparison of mildly and severely osteoarthritic regions of human femoral cartilage. Clinica Chimica Acta, 70, 87-95.

Partridge, S. M., Davis, H. F., and Adair, G. S. (1961). The chemistry of connective tissues 6 . The constitution of the chondroitin sulphate-protein complex in 
cartilage. Biochemical Journal, 79, 15-26.

Pasternack, S. G., Veis, A., and Breen, M. (1974). Solvent-dependent changes in proteoglycan subunit conformation in aqueous guanidine hydrochloride solutions. Journal of Biological Chemistry, 249, 2206-2211.

Pearson, J. P., and Mason, R. M. (1977). The stability of bovine nasal cartilage proteoglycans during isolation and storage. Biochimica et Biophysica Acta, 498, 176-188.

Poole, A. R., Barratt, M. E. J., and Fell, H. B. (1973). The role of soft connective tissue in the breakdown of pig articular cartilage cultivated in the presence of complement-sufficient antiserum to pig erythrocytes. II. Distribution of immunoglobulin G (IgG). International Archives of Allergy and Applied Immunology, 44, 469-488.

Poole, A. R., Hembry, R. M., and Dingle, J. T. (1974). Cathepsin D in cartilage: the immunohistochemical demonstration of extracellular enzyme in normal and pathological conditions. Journal of Cell Science, 14, 139-161.

Robinson, H. C., and Hopwood, J. J. (1973). The alkaline cleavage and borohydride reduction of cartilage proteoglycan. Biochemical Journal, 133, 457-470.

Rodén, L., and Armand, G. (1966). Structure of the chondroitin 4-sulfate-protein linkage region: isolation and characterisation of the disaccharide $3-O-\beta-\mathrm{D}-$ glucuronosyl-D-galactose. Journal of Biological Chemistry, 241, 65-70.

Rodén, L., and Smith, R. (1966). Structure of the neutral trisaccharide of the chondroitin 4-sulfate-protein linkage region. Journal of Biological Chemistry, 241, 5949-5954.

Rosenberg, L. (1974). Structure of cartilage proteoglycans. In Dynamics of Connective Tissue Macromolecules, edited by P. M. C. Burleigh and A. R. Poole, pp. 105-128. North-Holland Publishing, Amsterdam.

Rosenberg, L., Hellmann, W., and Kleinschmidt, A. K. (1970a). Macromolecular models of proteinpolysaccharides from bovine nasal cartilage based on electron microscopic studies. Journal of Biological Chemistry, 245, 4123-4130.

Rosenberg, L., Pal, S., and Beale, R. J. (1973). Proteoglycans from bovine proximal humeral articular cartilage. Journal of Biological Chemistry, 248, 36813690.

Rosenberg, L., Pal, S., Beale, R. J., and Schubert, M. (1970b). A comparison of proteinpolysaccharides of bovine nasal cartilage isolated and fractionated by different methods. Journal of Biological Chemistry, 245, 4112-4122.

Rosenberg, L., Wolfenstein-Todel, C., Margolis, R., Pal, S., and Strider, W. (1976). Proteoglycans from bovine proximal humeral articular cartilage: structural basis for the polydispersity of proteoglycan subunit. Journal of Biological Chemistry, 251, 6439-6444.

Roughley, P. J., and Mason, R. M. (1976). The electrophoretic heterogeneity of bovine nasal cartilage proteoglycans. Biochemical Journal, 157, 357-367.

Roughley, P. J., Murphy, G., and Barrett, A. J. (1978). Proteinase inhibitors of bovine nasal cartilage. Bio- chemical Journal, 169, 721-724.

Sajdera, S. W., and Hascall, V. C. (1969). Proteinpolysaccharide complex from bovine nasal cartilage: a comparison of low and high shear extraction procedures. Journal of Biological Chemistry, 244, 77-87.

Sapolsky, A. I., Howell, D. S., and Woessner, J. F., Jr. (1974). Neutral proteases and cathepsin $D$ in human articular cartilage. Journal of Clinical Investigation, 53, 1044-1053.

Sapolsky, A. I., Keiser, H., Howell, D. S., and Woessner, J. F., Jr. (1976). Metalloproteases of human articular cartilage that digest cartilage proteoglycan at neutral and acid pH. Journal of Clinical Investigation, 58, 1030-1041.

Seno, N., Anno, K., Yaegashi, Y., and Okayama, T. (1975). Microheterogeneity of chondroitin sulfates from various cartilages. Connective Tissue Research, 3 , 87-96.

Seno, N., Meyer, K., Anderson, B., and Hoffman, P. (1965). Variations in keratosulfates. Journal of Biological Chemistry, 240, 1005-1010.

Šmůnek, Z., and Muir, H. (1972). Changes in the protein-polysaccharides of pig articular cartilage during prenatal life, development and old age. Biochemical Journal, 126, 515-523.

Smith, J. W., Peters, T. J., and Serafini-Fracassini, A. (1967). Observations on the distribution of the proteinpolysaccharide and collagen in bovine articular cartilage. Journal of Cell Science, 2, 129-136.

Solursh, M., Vaerewyck, S. A., and Reiter, R. S. (1974). Depression by hyaluronic acid of glycosaminoglycan synthesis by cultured chick embryo chondrocytes. Developmental Biology, 41, 233-244.

Swann, D. A., Powell, S., Broadhurst, J., Sordillo, E., and Sotman, S. (1976). The formation of a stable complex between dissociated proteoglycan and hyaluronic acid in the absence of a link protein. Biochemical Journal, 157, 503-506.

Sweet, M. B. E., Thonar, E. J.-M. A., Immelman, A. R., and Solomon, L. (1977). Biochemical changes in progressive osteoarthrosis. Annals of the Rheumatic Diseases, 36, 387-398.

Toda, N., and Seno, N. (1970). Sialic acid in the keratan sulfate fraction from whale cartilage. Biochimica er Biophysica Acta, 208, 227-235.

Toole, B. P. (1973). Hyaluronate and hyaluronidase in morphogenesis and differentiation. American Zoologist, 13, 1061-1065.

Tsiganos, C. P., Hardingham, T. E., and Muir, H. (1972). Aggregation of cartilage proteoglycans. Biochemical Journal, 128, 121P.

Tsiganos, C. P., and Muir, H. (1967). A hybrid proteinpolysaccharide of keratan sulphate and chondroitin sulphate from pig laryngeal cartilage. Biochemical Journal, 104, 26c-28c.

Tsiganos, C. P., and Muir, H. (1969). Studies on proteinpolysaccharides from pig laryngeal cartilage: heterogeneity, fractionation and characterisation. Biochemical Journal, 113, 885-894.

Wasteson, $\AA$., and Lindahl, U. (1971). The distribution of sulphate residues in the chondroitin sulphate chain. Biochemical Journal, 125, 903-908. 
Wiebkin, O. W., Hardingham, T. E., and Muir, H. (1975). The interaction of proteoglycans and hyaluronic acid and the effect of hyaluronic acid on proteoglycan synthesis by chondrocytes of adult cartilage. In Dynamics of Connective Tissue Macromolecules, edited by P. M. C. Burleigh and A. R. Poole, pp. 81-104. North-Holland Publishing, Amsterdam.

Wiebkin, O. W., and Muir, H. (1973). The inhibition of sulphate incorporation in isolated adult chondrocytes by hyaluronic acid. FEBS Letters, 37, 42-46.
Wiebkin, O. W., and Muir, H. (1975). Influence of the cells on the pericellular environment: the effect of hyaluronic acid on proteoglycan synthesis and secretion by chondrocytes of adult cartilage. Philosophical Transactions of the Royal Society of London. Series B. Biological Sciences, 271, 283-291.

Wood, K. M., Wusteman, F. S., and Curtis, C. G. (1973). The degradation of intravenously injected chondroitin 4-sulphate in the rat. Biochemical Journal, 134, 10091013. 